\title{
Reflexões sobre o modelo de fiscalização sanitária nos portos, aeroportos e fronteiras do Brasil
}

Reflections about the sanitary inspection in ports, airports and borders of Brazil

\section{Maria das Graças Ramos Oliveira ${ }^{1}$}

\begin{abstract}
Resumo: A pesquisa teve como objetivo o estímulo à reflexão sobre os limitantes do controle sanitário dos portos, aeroportos e fronteiras, mediante a apresentação de uma análise do modelo de fiscalização sanitária exercido nas áreas de portos, aeroportos, fronteiras e recintos alfandegados do país. Foi feita uma análise dos dados de inspeções em ambientes e produtos, no espaço territorial da pesquisa. A fonte de pesquisa foi o sistema informatizado intitulado Programa Estatístico de Portos, Aeroportos e Fronteiras (ESTATPAF). Os resultados reforçam a ideia de que a responsabilidade sobre o estágio em que se encontra a fiscalização sanitária dos portos, aeroportos e pontos de fronteiras do país, ao invés de recair sobre a organização do Estado recai, principalmente, sobre o modelo de gestão da Anvisa, no caso específico, sobre a gestão da fiscalização sanitária exercida nos portos, aeroportos e fronteiras.
\end{abstract}

Palavras-chave: Portos; Aeroportos e Fronteiras; Controle Sanitário; Fiscalização

\begin{abstract}
The study aimed to stimulate reflection on limiting the sanitary control of ports, airports and borders, by presenting an analysis of the health model exercised in the areas of ports, airports, borders and customs areas of the country. an analysis of inspection data was made in environments and products, in the territorial space of the research. The research source was the electronic system called Statistical Programme of Ports, Airports and Borders (ESTATPAF). The results reinforce the idea that the responsibility of the status of which is the sanitary inspection of ports, airports and border points of the country, instead of falling back on the state organization rests mainly on the model management of ANVISA, in the specific case, on the management of health review carried out in ports, airports and borders
\end{abstract}

Keywords: Ports; Airports and Borders; Sanitary Control; Supervision

Resumen: La investigación tuvo como objetivo estimular la reflexión sobre la limitación del control sanitario de los puertos, aeropuertos y fronteras, mediante la presentación de un análisis del modelo de fiscalizacíon ejercido en las áreas de puertos, aeropuertos, fronteras y zonas aduaneras del país. Un análisis de los datos de la inspección fue tomada en entornos y productos, en el espacio territorial de la investigación. La fuente de investigación fue el sistema electrónico llamado Programa Estadístico de Puertos, Aeropuertos y Fronteras (ESTATPAF). Los resultados refuerzan la idea que la responsabilidad de la situación recae sobre la inspección sanitaria de puertos, aeropuertos y puntos fronterizos del país, al revés de estar sobre la organización del Estado y

\footnotetext{
${ }^{1}$ Farmacêutica, Especialista em Direito Sanitário. Especialista em Regulação Sanitária da Agência Nacional de Vigilância Sanitária (Anvisa). Brasília, Brasil. E-mail: maria.oliveira@anvisa.gov.br
} 
principalmente en el modelo de gestión de la ANVISA en el caso concreto, sobre la gestión de revisión sanitaria efectuada en puertos, aeropuertos y fronteras.

Palabras-Ilave: Puertos; Aeropuertos y Fronteras; Control Sanitario; Fiscalización

\section{Introdução}

Para contemplar o sistema federalista na elaboração constitucional, ocorre o estabelecimento das competências das entidades de poder que compõem a federação, característica chave da estrutura federal.

A Constituição brasileira que disciplinou o Estado federal foi a de 1891(Brasil, 1981), que além de instituir a forma federativa de Estado, instituiu a forma republicana de governo. O regime federalista continua a ser adotado atualmente no Brasil como cláusula pétrea $^{2}$ na Constituição Federal de 1988 (Brasil, 1988).

A configuração do Estado federal brasileiro é de uma federação com três níveis de governo - federal, estadual e municipal - autônomos quanto ao exercício do poder estatal, aos quais a Constituição determinou condutas específicas.

A Constituição de 1988 definiu, no seu artigo 18, um modelo não centralizador do poder para reger a organização político administrativa do país. ${ }^{3}$ Os municípios, já autônomos desde a Constituição de 1891, conquistaram a posição de ente federado, podendo, portanto, elaborar suas constituições municipais, na forma de leis orgânicas.

Desde a promulgação da Constituição de 1988, o direito à saúde assume conceituação ampla, indo ao encontro da garantia do direito a todos os cidadãos, indistintamente. O direito universal à saúde foi uma inovação do atual modelo constitucional e deve ser garantido mediante ações do Estado, operacionalizadas pelos organismos federados, os quais gozam de autonomia política e administrativa. Para tal, culminou com a criação do Sistema Único de Saúde (SUS), cujas diretrizes se voltam a garantir o direito à saúde mediante políticas públicas. Este evento marcante no setor da saúde - a criação do SUS - teve sua organização na forma de uma rede hierarquizada e

\footnotetext{
${ }^{2}$ Cláusulas pétreas são as disposições que não são susceptíveis de serem abolidas por emenda ou quaisquer modificações formais da Constituição. Diz o art. $1^{\circ}$ da Constituição: "A República Federativa do Brasil, formada pela União indissolúvel dos Estados e Municípios e do Distrito Federal, constitui-se em Estado Democrático de Direito e tem como fundamentos [...]". (Brasil, 1988).

3 "A organização político administrativa da República Federativa do Brasil compreende a União, os Estados, o Distrito Federal e os municípios, todos autônomos, nos termos desta Constituição." (Brasil, 1988).
} 
regionalizada de serviços e no artigo 200 da CF/88, a Vigilância Sanitária é definida, como atribuição do SUS. ${ }^{4}$

As ações de vigilância sanitária são consequência de políticas que incorporam, dentre outras medidas, a elaboração de normas e regulamentos que, não raro, esbarram em obstáculos, face aos conflitos de competência política e administrativa entre os responsáveis pela gestão dos diversos espaços de atuação.

Com a criação da Agência Nacional de Vigilância Sanitária (Anvisa), em 1999, surge um novo modo de gestão do setor, que se aproxima da proposta da reforma administrativa do Estado, uma vez que as agências reguladoras adotam modelo de gestão que vem ao encontro da Administração Pública Gerencial.

No caso da vigilância sanitária dos portos, aeroportos e fronteiras, o novo cenário da Administração Pública associa-se a um contexto de intensas mudanças nas relações internacionais, (re) significando o modo de agir do Estado.

Assim, no que respeita aos espaços fronteiriços do país, tema deste trabalho, a criação da Anvisa veio ao encontro da evolução tecnológica e das novas definições nascidas dos acordos internacionais, consequência do processo de globalização. Contudo, após anos da criação da autarquia, ainda não se logrou êxito na consecução de mecanismos eficazes para, solução dos conflitos político-administrativos que ocorrem no interior do setor, isso porque, sob o aspecto da repartição das competências dos entes federados, a fiscalização das áreas limítrofes do país está a cargo da Anvisa, em decorrência da competência concedida à União para exercer a vigilância dos portos, aeroportos e fronteiras.

Diante desse cenário, é que a pesquisa, cujos resultados ora se apresentam, foi pautada no sentido de gerar estímulo à reflexão sobre os limitantes do controle sanitário dos portos, aeroportos e fronteiras, mediante a apresentação de uma análise do modelo de fiscalização sanitária exercido nas áreas de portos, aeroportos, fronteiras e recintos alfandegados do país, a partir dos dispositivos legais que definem a repartição das competências entre os entes federativos.

\footnotetext{
${ }^{4}$ Art. 200:" Ao Sistema Único de Saúde compete, além de outras atribuições, nos termos da lei: II - executar as ações de vigilância sanitária e epidemiológica, bem como as de saúde do trabalhador". (Constituição da República Federativa do Brasil, 1988).
} 


\section{Metodologia}

A propósito de metodologia de trabalho, esta foi feita uma análise quantitativa das inspeções dos ambientes e produtos, nos Estados do Acre, Bahia, Espírito Santo, Mato Grosso do Sul. Pará, Rio de Janeiro, Rio Grande do Sul, Roraima, Santa Catarina e São Paulo, no período de janeiro a outubro do ano de 2008.

Realizou-se o levantamento dos registros das fiscalizações sanitárias, na forma de inspeções, efetuadas pelas unidades de Portos, Aeroportos e Fronteiras da Anvisa.

O âmbito de atuação da Vigilância Sanitária dentro do recorte deste estudo abrange o espaço territorial aquático, terrestre e aéreo.

O domínio marítimo ${ }^{5}$ abrange as zonas sob jurisdição nacional e compreende a faixa de 12 milhas marítimas contíguas ao território do país. Já o domínio aéreo compreende a atmosfera e o espaço extra-atmosférico. O domínio fluvial e lacustre compreende os rios e lagos que banham os países.

A fonte de pesquisa foi o sistema informatizado intitulado Programa Estatístico de Portos, Aeroportos e Fronteiras (ESTATPAF).

\section{Resultados e discussão}

O controle sanitário de portos, aeroportos, fronteiras se traduz na fiscalização de produtos, serviços e ambientes, em cooperação com outros órgãos competentes, dentre os quais se destacam a Receita Federal, o Ministério da Agricultura, Pecuária e Abastecimento e a Polícia Federal.

A posição secundária em que foi colocada a vigilância sanitária dos portos, aeroportos e pontos de fronteiras do país tem se modificado, gradualmente, e de forma positiva nos últimos anos, sobretudo, no aspecto relativo à busca de reconhecimento do papel da área para a população.

A prestação dos serviços sob controle sanitário deve ser antecedida pela Autorização de Funcionamento (Pompeu, 2007), ${ }^{6}$ que é o meio de regularização das

\footnotetext{
${ }^{5}$ O domínio marítimo está regulamentado na Convenção das Nações Unidas sobre Direito do Mar, de 1982. No Brasil está regulamentado pela Lei no 8.617, de 1993 (Brasil, 1993).

6 Para Cid Pompeu, a autorização, enquanto ato administrativo pode tomar dois sentidos: um lato sensu, no qual significa a outorga que o agente público "faz a outro agente público, à entidade da Administração ou a particular para desempenho de ato ou atividade material." ou, noutro sentido, é a outorga removedora de óbice importo pela lei "ao livre desenvolvimento de atividade individual" (Pompeu, 2007, p. 58). Diz a Lei $n^{\circ}$ 6.360/76, que dispõe sobre os produtos submetidos ao controle sanitário: Art. 50. "O funcionamento das empresas de que trata esta Lei dependerá de autorização do Ministério da Saúde, à vista da indicação da
} 
empresas interessadas, instituto este previsto no Direito Administrativo como de caráter discricionário e precário.

Quanto à fiscalização sanitária, esta pode ser didaticamente dividida em quatro categorias: de viajantes (orientação, vacinação, notificação de anormalidades clínicas a bordo), de cadáveres (liberação do translado de restos mortais), de produtos (inspeção de mercadorias sob importação ou exportação), de meios de transporte (inspeção de embarcações, aeronaves e de transportes terrestres) e de ambientes (controle de vetores, de resíduos, de água para uso humano etc.).

Durante a pesquisa, com o auxilio do sistema ESTATPAF, ${ }^{7}$ foram levantados os dados das fiscalizações realizadas em dez estados do país, no período de janeiro a outubro de 2008. Elegeram-se os meios de transporte como item de intervenção para a análise em razão da qualidade dos dados requerida, que somente esse item proporcionou.

Dos parâmetros apresentadas no sistema ESTATPAF (tabela 1), apenas no item transporte verificaram-se variáveis de entrada e saída, ou seja, veículos entrantes, contra inspeções realizadas. Essas duas informações foram imprescindíveis para a análise pretendida. Os estados escolhidos foram os que mostraram maior movimentação de veículos e produtos, no período.

atividade industrial respectiva, da natureza e espécie dos produtos e da comprovação da capacidade técnica, científica e operacional, e de outras exigências [...]" (Brasil, 1976).

7 Programa Estatístico de Portos, Aeroportos e Fronteiras (ESTATPAF). Está em fase de implantação um sistema que ira substituir $\mathrm{o}$ atual. 
Tabela 1 - Fiscalização Sanitária nos Portos, Aeroportos e Fronteiras dos Estados do Acre, Bahia, Espírito Santo, Mato Grosso do Sul, Pará, Rio de Janeiro, Rio Grande do Sul, Roraima, Santa Catarina e São Paulo (2009).

\begin{tabular}{|c|c|c|c|c|c|c|c|c|}
\hline & \multicolumn{4}{|c|}{ Entrada de meios de transporte } & \multicolumn{4}{|c|}{ Inspeção em meios de transporte } \\
\hline & Aeronaves & Embarcações & $\begin{array}{c}\text { Transporte } \\
\text { terrestre de } \\
\text { passageiros, } \\
\text { carga e passeio }\end{array}$ & $\begin{array}{l}\text { Transporte } \\
\text { terrestre de } \\
\text { carga - Eadi }\end{array}$ & Aeronaves & Embarcações & $\begin{array}{c}\text { Transporte } \\
\text { terrestre de } \\
\text { passageiros, } \\
\text { carga e passeio }\end{array}$ & $\begin{array}{c}\text { Transporte } \\
\text { terrestre de } \\
\text { carga - Eadi }\end{array}$ \\
\hline$A C$ & 1.201 & 127 & 137 & - & 684 & 129 & 2.282 & - \\
\hline $\mathrm{BA}$ & 32.378 & 3.112 & - & - & 3.702 & 977 & - & - \\
\hline ES & 8.574 & 4.420 & - & - & 649 & 857 & - & - \\
\hline MS & 4.371 & 3.303 & 122.643 & - & 2.978 & 879 & 11.109 & - \\
\hline PA & 13.189 & 1.341 & - & - & 3.822 & 731 & - & - \\
\hline RJ & 21.659 & 781 & - & - & 999 & 342 & - & - \\
\hline RS & 27.409 & 2.699 & 326.402 & - & 3.533 & 1.363 & 16.589 & - \\
\hline $\mathrm{RR}$ & 2.853 & 79 & 3.107 & - & 1.327 & 12 & 458 & - \\
\hline SC & 13.480 & 1.533 & 861 & - & 1.829 & 519 & 115 & - \\
\hline SP & 100.181 & 5.481 & - & - & 18 & 930 & - & - \\
\hline
\end{tabular}

Fonte: ESTATPAF,2009.

Do exame da planilha de dados do ESTATPAF, observou-se uma divisão em dois blocos: o primeiro, os dados de entrada de veículos, nos diversos modais (aéreo, terrestre e aquático) e os números relativos às inspeções realizadas nesses veículos durante o período considerado. O segundo bloco representava os números das inspeções nos elementos de infraestrutura portuária, aeroportuária e de fronteiras, contudo, sem relacioná-los a quaisquer parâmetros de entrada de dados.

Dessa constatação, nascem os primeiros elementos de discussão prática desta pesquisa. Questionou-se, então, o significado dos números das inspeções se esses não foram precedidos de estratégia fiscal, contendo indicadores e metas a serem alcançadas, pois, sem resposta a este questionamento, o modelo de fiscalização torna-se vazio de significado e não reflete o controle sanitário supostamente pretendido. Por essa razão, o estudo realizou-se em torno dos dados de entrada de veículos e relacioná-los com as inspeções correspondentes.

Como resultado do estudo, encontraram-se números díspares, cuja explicação não poderia estar pautada em critérios de demanda, se considerado o fato de que não foi encontrada lógica alguma entre as entradas de veículos e o número de inspeções. Por 
exemplo, à entrada de 137 veículos terrestres (de cargas ou passageiros) através dos pontos de passagem de fronteiras, foi realizado um total de 2.282 inspeções, ou seja, em média, um mesmo veiculo teria sido inspecionado cerca de 16 vezes, no período. Já no caso do Estado do Mato Grosso do Sul, teriam sido inspecionados apenas $9 \%$ deles ${ }^{8}$. Concluiu-se, então, que não existia padronização de procedimentos entre os estados, quanto ao universo dos elementos fiscalizados.

Diante do elevado numero de veículos entrantes (122.643) relativos ao estado do Mato Grosso do Sul, contra 11.109 inspeções realizadas, pressupõe-se logo à primeira vista, que houve falha nos registros, ou, essas operações demandaram a ocupação de grande número de servidores para a sua execução, hipóteses que necessitariam de uma análise aprofundada, o que foge ao objeto deste estudo.

Foram tomados como amostras os estados do Rio de Janeiro e São Paulo, nos seus elementos de entrada e inspeções de aeronaves e embarcações, no período estudado. Do total de 781 embarcações entrantes pelo porto do Rio de Janeiro, 342 foram inspecionadas, ou seja, aproximadamente, $50 \%$ dos veículos aquáticos entrantes.

Em contrapartida, no que se refere a aeronaves, apenas cerca de $4 \%$ das entrantes pelo Aeroporto Internacional do Rio de Janeiro foram inspecionadas. No estado de São Paulo, das 5.481 embarcações entrantes, 930 foram inspecionadas, ou seja, cerca de $25 \%$ delas. Já com relação às aeronaves, cerca de $1 \%$ foi inspecionada. Ainda que não guardasse proporcionalidade entre os dois estados, a superioridade do número de inspeções em embarcações com relação a aeronaves foi coincidente.

Se considerado o fato já exposto neste texto, de que a movimentação de cargas importadas ou sob exportação se processa, em sua grande parte, através dos portos e, considerando ainda, serem os estado do Rio de Janeiro e de São Paulo, os maiores pontos de entrada e saída do país, pode-se supor que seja esta vocação da área portuária a justificativa para a priorização das inspeções em embarcações.

O número ínfimo de inspeções em aeronaves é sintomático da insuficiência de planejamento uma vez que, outras fontes de risco sanitário devem ser consideradas: A entrada e saída de passageiros, por exemplo, que ocorrem, na sua maioria, por via aérea

\footnotetext{
${ }^{8} \mathrm{~A}$ grande disparidade entre os números não permitiu a escolha de um parâmetro de grandeza (unidades, percentuais etc.) para a representação dos resultados do estudo.
} 
pode se transformar em vetor de doenças ou agravos transmissíveis, não só diretamente, como por meio de alimentos e objetos deixados a bordo.

Diante das constatações da pesquisa, torna-se patente o fato de que as ações de fiscalização dos portos, aeroportos e pontos de fronteiras do país não estão sustentadas por bases técnicas e científicas sólidas, capazes de dar respostas quanto à suficiência dos recursos financeiros, materiais e humanos necessários ao seu planejamento.

\section{Conclusão}

O advento da criação da Agência Nacional de Vigilância Sanitária trouxe, no bojo do seu objeto, o propósito de minimizar os reflexos dos conflitos federativos sobre a saúde. No caso específico da vigilância sanitária dos pontos de entrada do país, as diretrizes para o alcance das melhorias ainda não se mostram claramente traçadas, dado que se evidenciam fronteiras administrativas entre as diferentes esferas estatais que dificultam, sobremaneira, o exercício pleno do poder do Estado nas ações de vigilância sanitária no espaço territorial estudado.

Considera-se que a hipótese da influência da repartição dos entes federados sobre o modelo de fiscalização dos portos, aeroportos e pontos de fronteira do país não carrega sobre si exclusividade do ônus diante do modelo incipiente das ações de fiscalização, considerando-se que o arcabouço legal vigente resguarda o instituto da cooperação entre os diferentes entes, sem margem a dúvidas quanto à legitimidade do uso desta prerrogativa legal.

O resultado da metodologia aplicada reforçou a ideia de que a hipótese da responsabilidade sobre o estágio em que se encontra a fiscalização sanitária dos portos, aeroportos e pontos de fronteiras do país, ao invés de recair sobre a organização do Estado recai, principalmente, sobre o modelo de gestão da Anvisa, no caso específico, sobre a frágil gestão da fiscalização sanitária exercida nos portos, aeroportos e fronteiras.

Sustenta-se a ideia de que esforços devem ser desprendidos no sentido do aproveitamento da prerrogativa legal da cooperação, uma proposta clara de democratização política e administrativa do Estado, consoante o modelo federativo pelo qual optou o país. 


\section{Referências bibliográficas}

BRASIL. Constituição da República Federativa do Brasil de 1891. Disponível em: http://www2.camara.leg.br/legin/fed/consti/1824-1899/constituicao-35081-24-fevereiro1891-532699-publicacaooriginal-15017-pl.html. Acesso em: 24 nov. 2014.

BRASIL. Constituição da República Federativa do Brasil de 1988. São Paulo: Revista dos Tribunais, 2008.

POMPEU, C. T. Autorização Administrativa. São Paulo: Revista dos Tribunais, 2007. 